Research Paper

\title{
Assessment of Anti-Tumor potential and safety of application of Glutathione stabilized Gold Nanoparticles conjugated with Chemotherapeutics
}

\author{
Karol P. Steckiewicz ${ }^{1 *}$, Ewelina Barcinska ${ }^{1 *}$, Katarzyna Sobczak², Ewelina Tomczyk², Michał Wojcik², \\ Iwona Inkielewicz-Stepniak ${ }^{\circledR}$ \\ 1. Chair and Department of Medical Chemistry, Medical University of Gdansk, Debinki street 1, 80-211 Gdansk, Poland. \\ 2. Faculty of Chemistry, University of Warsaw, Pasteura 1, 02-093 Warsaw, Poland. \\ *These authors contributed equally to this work. \\ $\square$ Corresponding author: Prof. Iwona Inkielewicz-Stepniak Ph.D. E-mail: iinkiel@gumed.edu.pl. Telephone: +4858 3591450 \\ (1) The author(s). This is an open access article distributed under the terms of the Creative Commons Attribution License (https://creativecommons.org/licenses/by/4.0/). \\ See http://ivyspring.com/terms for full terms and conditions.
}

Received: 2019.10.01; Accepted: 2020.01.08; Published: 2020.03.12

\begin{abstract}
Due to the high toxicity of currently used chemotherapeutics, novel methods of cancer treatment are needed. Gold nanoparticles (AuNPs) seem to be an interesting alternative due to penetration through biological membranes and systemic barriers. AuNPs as carriers of chemotherapeutics allow for reduced concentrations whilst maintaining the expected effect, and thus reducing the costs of therapy and adverse effects. We synthesized AuNPs stabilized with reduced glutathione (GSH) and conjugated with doxorubicin (DOX), gemcitabine (GEM) or cytarabine (CTA). This is the first study in which cytarabine-AuNPs were synthesized and characterized. Transmission electron microscopy (TEM), thermogravimetric analysis (TGA), nuclear magnetic resonance spectroscopy (NMR) and highperformance liquid chromatography (HPLC) were used to chemically characterize obtained nanoparticles. Antitumor activity and safety of application were assessed by MTT assay in in vitro model (human osteosarcoma cells -143B, human osteoblast- hFOB1.19, breast cancer cells - MCF7, breast epithelial cells - MCF10A, pancreatic cancer cells - PANC-1, and pancreatic cells - hTERT-HPNE cells). We have shown that cellular response varies according to the type and concentration of AuNPs. At some concentrations, we were able to show selective cytotoxicity of our AuNPs conjugates only to cancer cell lines. Synthesized nanoparticles were more cytotoxic to tumor cell lines than chemotherapeutics alone.
\end{abstract}

Key words: Gold nanoparticles; Cancer; Drug deliver platform; Gold nanoparticles conjugate; Chemotherapeutic

\section{Introduction}

Cancer is one of the leading causes of death and emerging epidemiological problem in clinical practice furthermore cancer treatment is expensive [1,2]. AuNPs, that have established a role in nanotechnology, may be a possible answer to that matter. It has been proven that AuNPs may be used in cancer diagnostic and therapy [3,4]. They can penetrate through cellular membranes, which is crucial for biomedical applications [5]. Furthermore, AuNPs as drug delivery platforms can accumulate in the cancer microenvironment, which protects healthy tissue [6]. Importantly, AuNPs can be efficient in drug-resistant neoplasm [7]. Another advantage of the usage of AuNPs is a variety of sizes and possible surface modifications, which greatly expands their clinical application [8-10]. AuNPs have also good safety-profile [11]. Furthermore, it has been shown that GSH stabilized AuNPs have good biocompatibility profile and low immunogenicity [12]. Moreover, GSH as a peptide present in each cell can increase the biocompatibility of possessed AuNPs, which will be beneficial for potential applications [13].

Pancreatic cancer, osteosarcoma, and breast cancer are types of cancer were different oncological approaches may be used. Pancreatic cancer is 
associated with poor prognosis $(6 \%$ of 5-years survival rate) [14]. There are several treatment options for this cancer: surgery, radiotherapy, chemotherapy or combination of those [14]. Among the others, gemcitabine (GEM) is used in chemotherapy for pancreatic cancer [14]. Unfortunately, GEM has severe side-effects, among the others: nausea, mielosuppression, liver damage or heart failure which may decrease patient quality of life [15]. Pancreatic cancer is thought to become the second most popular type of cancer in 2030 and the average cost of lifetime treatment per patient is as high as $\$ 65335[16,17]$. Another cancer considered with poor outcome is osteosarcoma, which is one of the most common cancers of the youth [18]. In general treatment options are similar to pancreatic cancer (surgery, chemotherapy, radiotherapy) [18]. Treatment of osteosarcoma in many cases requires amputation, which severely decreased the patient's quality of life. One of the agents used in osteosarcoma therapy is doxorubicin (DOX) [18]. Also, it has been proven that AuNPs may be cytotoxic to osteosarcoma cell lines [19]. For breast cancer apart from the "classical" treatment, we can use hormone-blocking therapy and monoclonal antibodies against described molecular targets. DOX and cytarabine (CTA) are effective drugs in breast cancer therapy [20,21]. Unfortunately, both drugs have serious aftereffects. For DOX it will be mielosuppression, cardiotoxicity hair loos and others [22]. Usage of CTA can lead to brain damage, mielosuppression, gastrointestinal tract disturbances and others [23]. Surgery with healthy tissue margin typically gives the best treatment outcome; however, it is limited only to small tumors. Thus, chemotherapy still is one of the main treatment strategies in oncology. However, due to multidrug resistance of cancer and poor penetration of active agents through the tumor, its effectiveness is limited. Thus, novel drug delivery platforms, such as AuNPs, may be an interesting solution to this problem.

In this research we assessed the anti-tumor potential of GSH stabilized AuNPs conjugated with chemotherapeutics (DOX, CTA, GEM). As chemotherapeutics have severe side effects and limited effectiveness we tried to overcome their disadvantages by using AuNPs as drug delivery platforms. Our modification allows using a smaller concentration (dose) of a drug, which will increase patients' comfort, also better penetration may upsurge the efficiency of treatment.

Effectiveness against pancreatic adenocarcinoma, breast cancer, and osteosarcoma cell lines was evaluated. We also assessed the safety of AuNPs application by in vitro cytotoxicity assay on non-transformed cell lines.

\section{Materials and methods}

\section{Synthesis}

\section{Synthesis of AuNPs stabilized with GSH}

$93.5 \mu \mathrm{L}(0.135 \mathrm{mmol})$ of $30 \%$ chloroauric acid solution $\left(\mathrm{HAuCl}_{4}\right)$ was diluted using $26 \mathrm{~mL}$ of distilled water. The reaction mixture was placed in a water/ice bath and then $162 \mathrm{mg}(0.537 \mathrm{mmol})$ of reduced glutathione was added slowly in small portions. The solution turned from light yellow through brown into transparent with white suspension. After 1.5 hours a few drops of a saturated solution of sodium bicarbonate was added, which caused an increase of $\mathrm{pH}$ and consequently disappearance of the precipitate. Next, $50 \mathrm{mg}(1.322$ mmol) of $\mathrm{NaBH}_{4}$ dissolved in $6.5 \mathrm{~mL}$ of water was added quickly with high-speed magnetic stirring. The solution turned brown and the reaction mixture was stirred an additional 2 hours. Then, $20 \mathrm{~mL}$ of methanol was added to precipitate nanoparticles. The precipitate was centrifuged (5000 rpm, $10 \mathrm{~min})$ washed with methanol: water 1:1 mixture and dissolved in $1 \mathrm{~mL}$ of distilled water. The significant concentration of nanoparticles left in supernatant and was subjected to additional precipitation. The obtained supernatant was mixed with $55 \mathrm{~mL}$ of methanol and was centrifuged (10000 rpm, $15 \mathrm{~min}$.) yielding brown sediments. The precipitate was washed with methanol: water 4:1 mixture and was dried. The additional precipitate was used in this study. Then nanoparticles were precipitated an additional two times. Resulted precipitates were left to dry in the air.

\section{Synthesis of AuNPs stabilized with GSH and DOX}

$4 \mathrm{mg}$ of AuNPs stabilized with GSH were dissolved in $0.4 \mathrm{~mL}$ of distilled water. Then, $2 \mathrm{~mL}$ of prepared DOX water solution $(1 \mathrm{mg} / \mathrm{mL})$ was added slowly. The reaction mixture was stirred 12 hours and then nanoparticles were purified using centrifugal filters (Amicon ${ }^{\circledR}$ Ultra $0.5 \mathrm{~mL}$ ) in a centrifuge (10000 rpm, $5 \mathrm{~min}$ ) and washed two times with PBS.

\section{AuNPs stabilized with GSH and GEM}

$20 \mathrm{mg}$ of AuNPs stabilized with GSH were dissolved in $2 \mathrm{~mL}$ of distilled water. Then, $1 \mathrm{mg}(0.003$ $\mathrm{mmol}$ ) of GEM dissolved in $1 \mathrm{ml}$ of water was added and the reaction was mixed for 12 hours. Next, nanoparticles were purified using centrifugal filters (Amicon ${ }^{\circledR}$ Ultra $0.5 \mathrm{~mL}$ ) in a centrifuge $(10000 \mathrm{rpm}, 5$ $\min )$.

\section{AuNPs stabilized with GSH and CTA}

$20 \mathrm{mg}$ of AuNPs stabilized with GSH were dissolved in $2 \mathrm{~mL}$ of distilled water. Then $1 \mathrm{mg}(0.004$ 
mmol) of CTA dissolved in $1 \mathrm{~mL}$ of water was introduced and the reaction was mixed for 12 hours. Next, nanoparticles were purified using centrifugal filters (Amicon ${ }^{\circledR}$ Ultra $0.5 \mathrm{~mL}$ ) in a centrifuge $(10000$ rpm, 5 min).

\section{Cell culture}

143B (ATCC CRL-8303) were cultured in Minimum essential medium (Eagle) with 0.015 $\mathrm{mg} / \mathrm{mL}$ 5-bromo-2'-deoxyuridine. Media was supplemented with $10 \%$ of heat-inactivated fetal bovine serum (FBS) and $1 \%$ of penicillin and streptomycin (P/S) hFOB 1.19 (ATCC CRL-11372) were cultured in 1:1 mixture of Ham's F12 Medium and Dulbecco's Modified Eagle's Medium (DMEM/ F12) with $2,5 \mathrm{mM}$ of L-glutamine. The media was supplemented with $10 \%$ of FBS and $1 \%$ of $\mathrm{P} / \mathrm{S}$. hTERT-HPNE (ATCC CRL-4023) were cultured in DMEM with $2 \mathrm{mM}$ of L-glutamine and Medium M3 base in ratio 3:1. Media was supplemented with $5 \%$ of FBS, $10 \mathrm{ng} / \mathrm{mL}$ of EGF, $1 \mathrm{~g} / \mathrm{L}$ of D-glucose, $750 \mathrm{ng} / \mathrm{mL}$ of puromycin and $1 \%$ of P/S. MCF 10A (ATCC HTB-2 2) were cultured in DMEM/F12 media supplemented with $5 \%$ of horse serum, $20 \mathrm{ng} / \mathrm{mL}$ of EGF, $0,5 \mathrm{mg} /$ $\mathrm{mL}$ of hydrocortisone, $100 \mathrm{ng} / \mathrm{mL}$ of cholera toxin, 10 $\mathrm{g} / \mathrm{mL}$ of insulin and $1 \%$ of P/S. MCF 7 (ATCC CRL10317) were cultured in DMEM (4mM L-glutamine and $4500 \mathrm{mg} / \mathrm{L}$ of glucose). The media was supplemented with $10 \%$ of FBS and $1 \%$ of P/S. PANC 1 (ATCC CRL-1496) were cultured in DMEM (4mM L-glutamine and $4500 \mathrm{mg} / \mathrm{L}$ of glucose). The media was supplemented with $10 \%$ of FBS and $1 \%$ of P/S. All cells were possessed from the American Type Culture Collection. Cells were kept in T-75 flask under the sterile condition at $37^{\circ} \mathrm{C}$ in a humidified atmosphere of $5 \%$ of $\mathrm{CO}_{2}$ (medium renewal every 2 days). When confluent cells were detached with a trypsin-EDTA solution and subcultivated according to ATCC guidelines.

\section{Treatments}

Each time just before experiment new dilutions of synthesized AuNPs in FBS-free media were prepared. The stock solution was shaken well to ensure an equal dispersion of AuNPs. Cells were incubated with $1,10,25,50$ and $100 \mu \mathrm{g} / \mathrm{mL}$ of all synthesized nanoparticles (AuNPs-GSH, AuNPsGSH-GEM, AuNPs-GSH-DOX, AuNPs-GSH-CTA). Prior to incubation solutions were shaken in order to prevent agglomeration of investigated AuNPs. Control cells were kept in FBS-free media without AuNPs addition. Cells were incubated in $37^{\circ} \mathrm{C}, 5 \%$ $\mathrm{CO}_{2}$ for $24 \mathrm{~h}$.

\section{MTT assay}

Cell viability was measured by MTT assay with a previously established method [19,24]. Briefly, cells were seeded into a 96-well dish (density $1 \times 10^{4}$ cells/ well). After $24 \mathrm{~h}$ cells were incubated with synthesized AuNPs and chemotherapeutics as described in the "Treatments" section. After $24 \mathrm{~h}$ solution watersoluble tetrazolium salt was added to a final concentration of $0.5 \mathrm{mg} / \mathrm{mL}$. Next, the plate was incubated for $2 \mathrm{~h}$ in standard condition. Formazan crystals were diluted in dimethyl sulfoxide. Cell viability was assessed by absorbance measurements. Absorbance values were adjusted with blank NPs. The viability of control cells was set to $100 \%$.

\section{Statistical analysis}

All statistical analysis was performed with GraphPad Prism 5 software (GraphPad Software, Inc., USA). Statistical analysis was determined by a one-way analysis of variance (ANOVA) and Tukey's posthoc test.

\section{Results}

\section{AuNPs characteristic}

\section{AuNPs stabilized with GSH (AuNPs-GSH)}

To determine the size and monodispersity of obtained nanoparticles we conducted TEM measurements. Figure 1 shows the TEM image of AuNPs (Figure 1a) and histograms of the size distribution (Figure $1 \mathrm{~b}$ ). The obtained nanoparticles have an average diameter of about $2.1+/-0.3 \mathrm{~nm}$.

The presence of GSH on the surface of nanoparticles has been confirmed by thermogravimetric analysis. The given thermogram (Figure 2) shows the weight loss of the sample during heating (red line). The first derivative of TGA curve (blue line) shows a single sharp peak in the temperature range $220-250^{\circ} \mathrm{C}$. It corresponds to the rapid decomposition of nanoparticles as a result of the loss of GSH from the surface of nanoparticles. This analysis showed that GSH is $\sim 24 \%$ of the mass of AuNPs.

The presence of GSH on the surface of the nanoparticles was also confirmed by ${ }^{1} \mathrm{H}$ NMR spectra (Figure 3a), for comparison spectra of GSH is shown in Figure 3b. In Figure 3a there are clearly visible four signals characteristic for GSH (strong signal $3.42 \mathrm{ppm}$ arises from methanol). All signals are broadened which is characteristic for NMR spectra protons from molecules conjugated to the surface of nanoparticles (no sharp signals indicate that sample was purified properly and there is no unbounded GSH). Signals at $2.30 \mathrm{ppm}, 2.69 \mathrm{ppm}$, and $3.89 \mathrm{ppm}$ are assigned respectively to protons from carbons 3,4 and 9 . The broad signal at $3.89 \mathrm{ppm}$ is probably a screening signal from proton from carbon 2, which should 
appear at $3.84 \mathrm{ppm}$. Protons from carbons 6 and 7 are in $\beta$ and a position to a thiol group, which is located in direct neighborhood to gold atoms, which cannot be analyzed by $1 \mathrm{D}$ spectra. (a)

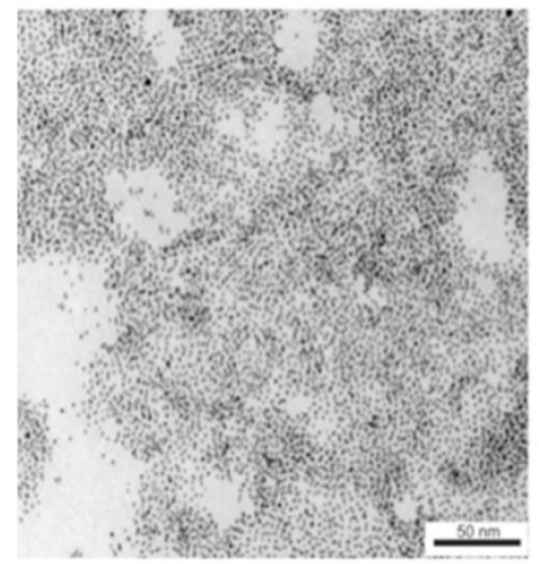

(b)

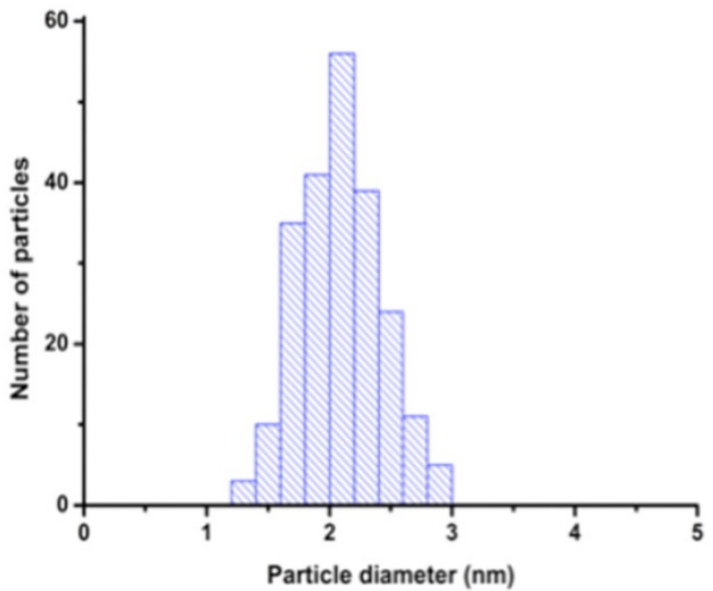

Figure 1. (a) AuNPs-GSH TEM image and (b) AuNPs-GSH histogram of size distribution. Scale bar corresponds to $50 \mathrm{~nm}$.

(a)

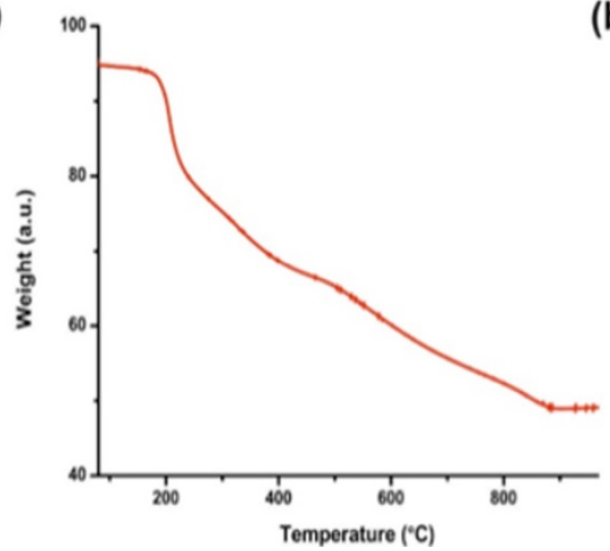

(b)

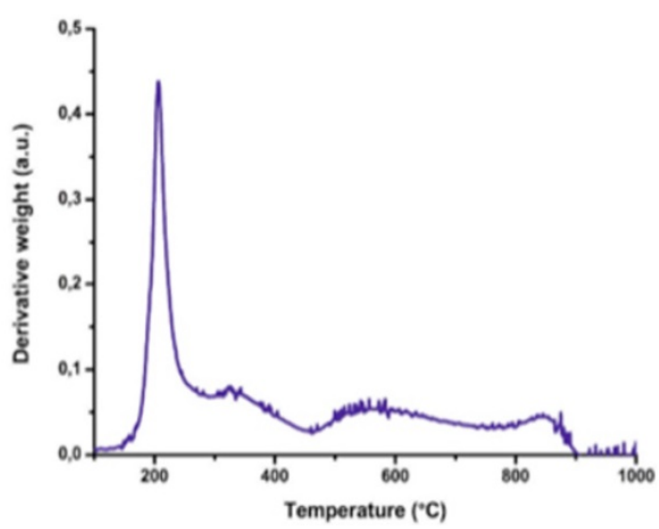

Figure 2. TGA analysis of AuNPs-GSH: (a) TGA curves of the studied sample and (b) the first derivative of its weight loss.

(a)

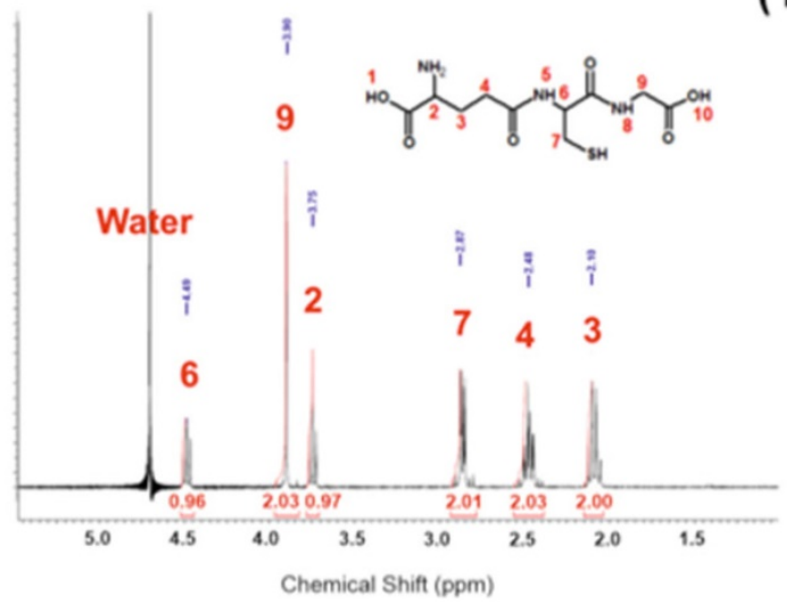

(b)

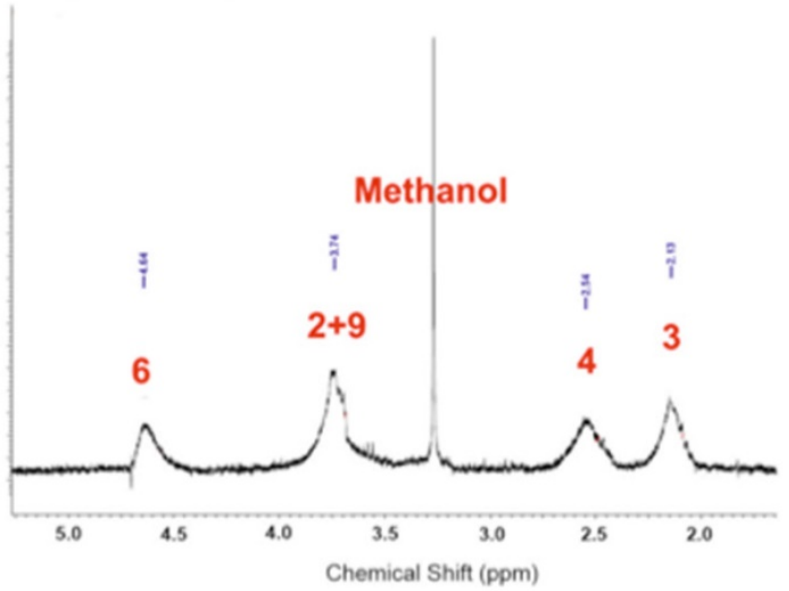

Figure 3. (a) $1 \mathrm{H}$ NMR of AuNPs-GSH (b) simulation of $1 \mathrm{H}$ NMR spectra of GSH. 
(a)

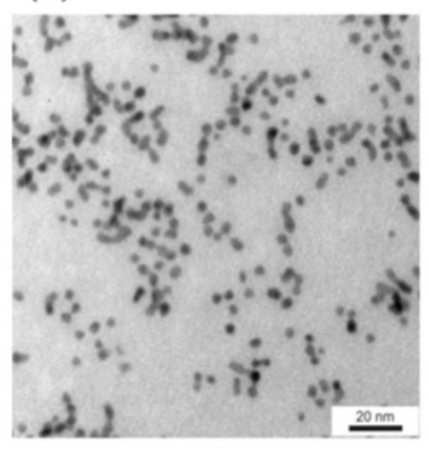

(b)

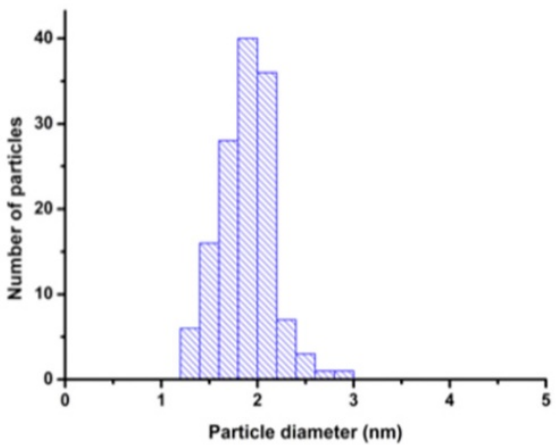

Figure 4. (a) TEM image and (b) histogram of NPs size distribution for AuNPs-GSH-DOX. Scale bar corresponds to $20 \mathrm{~nm}$.

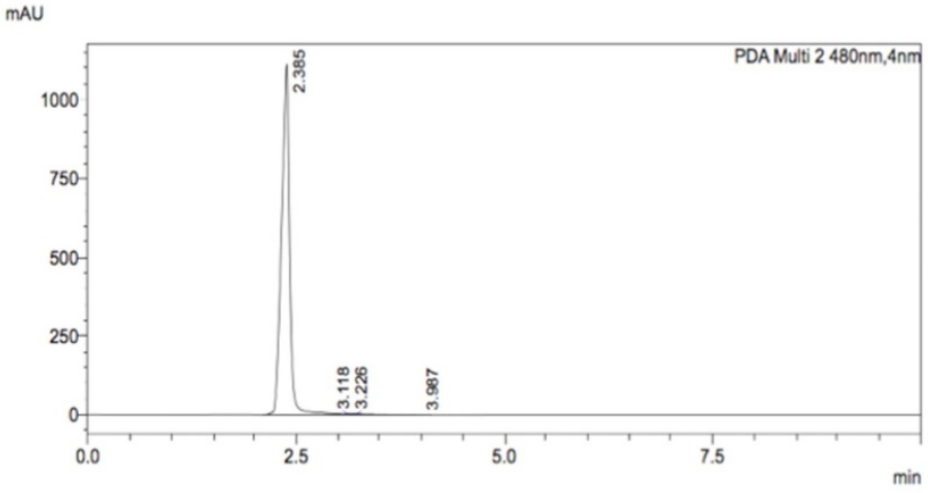

Figure 5. HPLC chromatogram of decomposed AuNPs-GSH-DOX solution.

AuNPs stabilized with GSH and DOX (AuNPs-GSH-DOX)

Figure 4 shows the TEM image (Figure 4a) and the histogram of the size distribution (Figure $4 b$ ) of nanoparticles. AuNPs-GSH-DOX have an average diameter of about $1.9+/-0.3 \mathrm{~nm}$ after the surface modification. The lower diameter value of these nanoparticles is related to lower contrast characteristics for samples with higher organic fraction concentration.

Sample of these nanoparticles was treated with iodine in order to break bonds between nanoparticles and ligands. Ligands solution was separated from nanoparticles aggregates and HPLC measurement was performed. The mobile phase consisted of $10 \mathrm{mM}$ $\mathrm{KH}_{2} \mathrm{PO} 4$ and $0.1 \%(\mathrm{v} / \mathrm{v})$ trifluoroacetic acid in water and acetonitrile as the organic phase. A gradient method was used in which the mobile phase started as $75 \%$ aqueous phase and $25 \%$ of the organic phase and changed in a linear manner to $60 / 40$ within 7 minutes. Peaks were monitored using a UV-VIS detector. Figure 5 shows a strong signal (2.385 $\mathrm{min})$, which is characteristic of DOX.
AuNPs stabilized with GSH and GEM (AuNPs-GSH-GEM)

Figure 6 shows the TEM image (Figure 6a) and the histogram of the size distribution (Figure $6 \mathrm{~b}$ ). The obtained nanoparticles have an average diameter of about $2.11+/-0.33 \mathrm{~nm}$.

\section{AuNPs stabilized with GSH and CTA (AuNPs-GSH-CTA)}

Figure 7 shows the TEM image (Figure 7a) and the histogram of the size distribution (Figure $7 b$ ). AuNPs-GSH-CTA have an average diameter of about $2.10+/-0.35 \mathrm{~nm}$. The lower diameter value of these nanoparticles is related to lower contrast characteristics for samples with higher organic faction concentration.

\section{AuNPs decreased the viability of the cells in a concentration-dependent manner}

AuNPs-GSH-DOX and AuNPs-GSH-GEM and all AuNPs-GSH-CTA decreased the viability of 143B cells. All tested AuNPs decreased the viability of hFOB 1.19 cells. The highest impact on 143B cells viability had AuNPs-GSH-CTA; this AuNPs in the concentration of $100 \mu \mathrm{g} / \mathrm{mL}$ demonstrated approximately $45 \%$ decreased viability of $143 \mathrm{~B}$ cells. 
In contrast, the highest impact on the viability of hFOB 1.19 cells had AuNPs-GSH-GEM (in the concentration of $100 \mu \mathrm{g} / \mathrm{mL}$ ). Interestingly, in lower concentrations $(1,10 \mu \mathrm{g} / \mathrm{mL}) \mathrm{hFOB} 1.19$ were more susceptible to AuNPs than 143B cells (Figure 8).

All tested AuNPs decreased the viability of PNAC-1 and hTERT-HPNE cells in a concentrationdependent manner. Importantly, hTERT-HPNE cells were more resistant to AuNPs than PANC-1 cells. The highest impact on PANC-1 viability had AuNPsGSH-GEM. AuNPs-GSH-CTA to around $30 \%$ and AuNPs-GSH-GEM decreased the viability of the cells to around $25 \%$. Similarly for hTERT-HPNE AuNPsGSH-CTA and AuNPs-GSH-GEM decreased the viability of the cells to around $45 \%$ (Figure 8).

All tested AuNPs decreased the viability of MCF7 cells and all tested AuNPs apart from AuNPs-GSH decreased viability of MCF10A cells. MCF10A were more resistant to AuNPs than MCF7 cells. The highest impact on MCF7 cells viability had AuNPs-GSH-GEM (decreased viability to around 25\%). AuNPs-GSH-DOX and AuNPs-GSH-GEM in $100 \mu \mathrm{g} / \mathrm{mL}$ concentrations decreased viability of MCF10A cells to $50 \%$ (Figure 8).

We have proven that AuNPs-GSH-DOX in concentration $1 \mu \mathrm{g} / \mathrm{mL}$, AuNPs-GSH-CTA in concentration $1 \mu \mathrm{g} / \mathrm{mL}$ and AuNPs-GSH-GEM in concentration $10 \mu \mathrm{g} / \mathrm{mL}$ are selectively cytotoxic to osteosarcoma cell line (143B) in comparison to non-transformed cells. AuNPs-GSH-GEM in concentration $1 \mu \mathrm{g} / \mathrm{mL}$ is selectively cytotoxic against pancreatic ductal adenocarcinoma cells (PANC-1). AuNPs-GSH-CTA in concentration 1 and $10 \mu \mathrm{g} / \mathrm{mL}$ is selectively cytotoxic to epithelial breast adenocarcinoma cells (MCF7).

Generally, cancer cell lines (143B, PANC1, MCF7) were more susceptible to our conjugates that non-transformed cell lines (hFOB1.19, hTERT-HPNE, MCF10A). In Figure 8 red boxes indicate selective cytotoxicity of AuNPs only to cancer cells (in comparison to non-transformed cells).

As a reference, we assessed the impact of chemotherapeutics on the viability of cancer cell lines (Figure 9). DOX in a concentration equal or higher $0.49 \mu \mathrm{g} / \mathrm{mL}$ decreased the viability of $143 \mathrm{~B}$ and MCF7 cells and in a concentration equal or higher 0.99 $\mu \mathrm{g} / \mathrm{mL}$ of PANC1 cells. CTA decreased the viability of 143B, PANC-1 and MCF7 cells in concentrations equal to or higher than $2.47 \mu \mathrm{g} / \mathrm{mL}$. GEM significantly decreased the viability of $143 \mathrm{~B}$ cells in a concentration equal or higher $0.49 \mu \mathrm{g} / \mathrm{mL}$, PANC-1 $2.47 \mu \mathrm{g} / \mathrm{mL}$ and MCF7 $0.99 \mu \mathrm{g} / \mathrm{mL}$. (a)

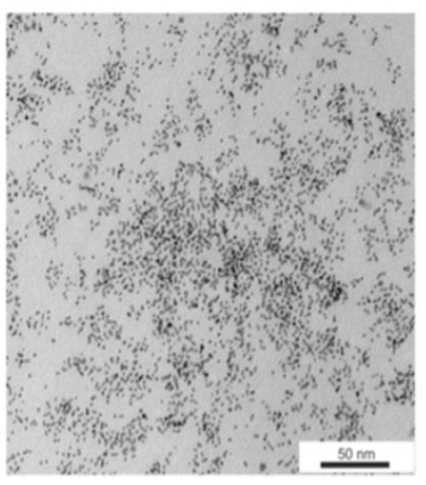

(b)

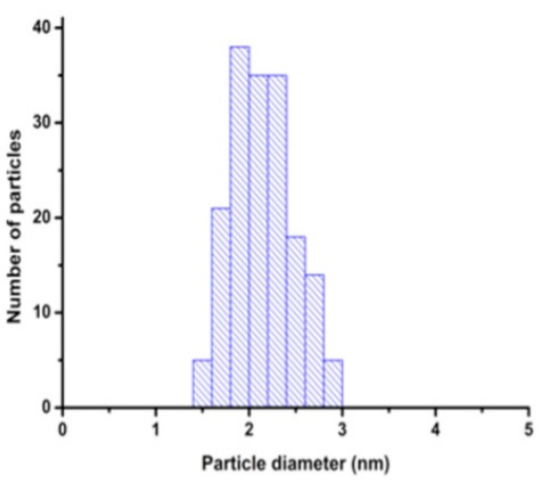

Figure 6. (a) TEM image and (b) histogram of NPs size distribution for AuNPs-GSH-GEM. Scale bar corresponds to $50 \mathrm{~nm}$.

(a)

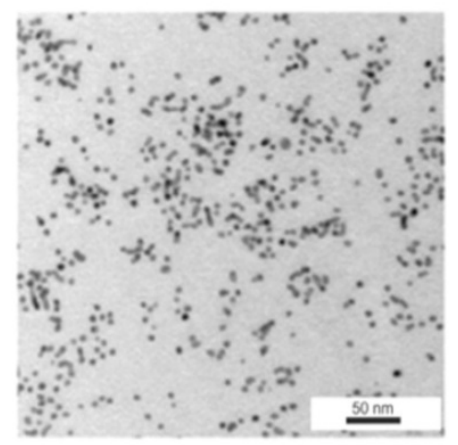

(b)

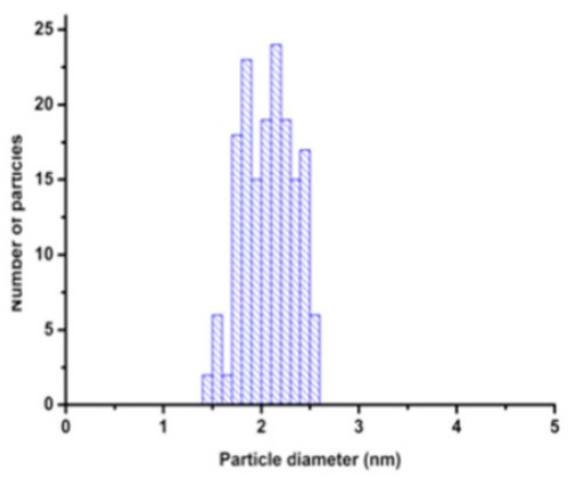

Figure 7. (a) TEM image and (b) histogram of NPs size distribution for AuNPs-GSH-CTA. Scale bar corresponds to $50 \mathrm{~nm}$. 
a) $143 \mathrm{~B}$

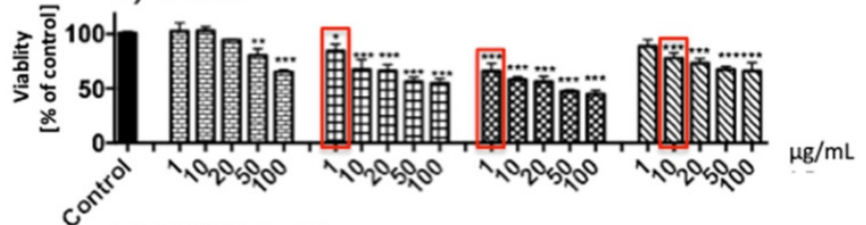

b) hFOB 1.19

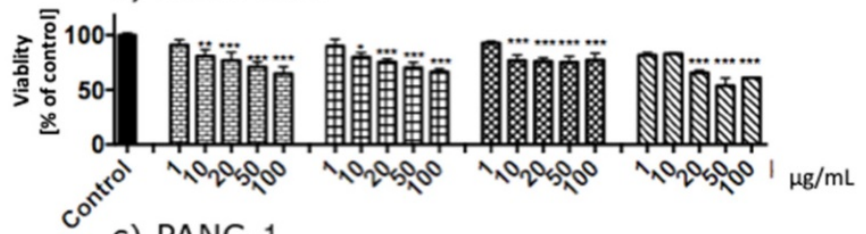

c) PANC-1
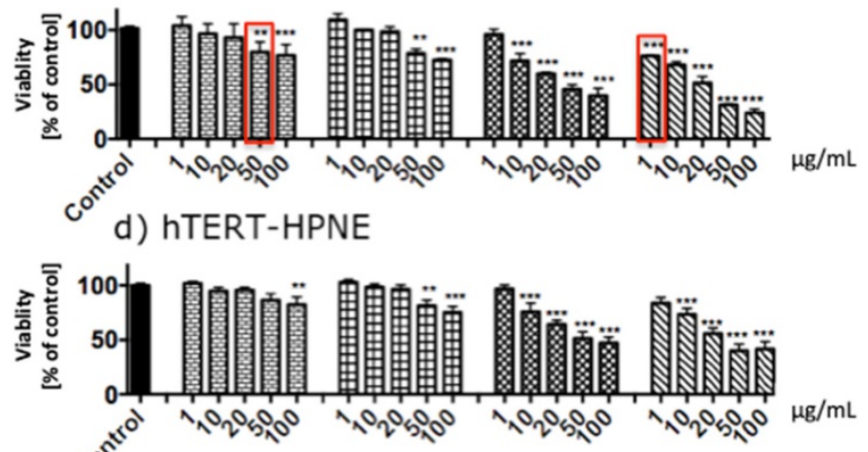

e) MCF7
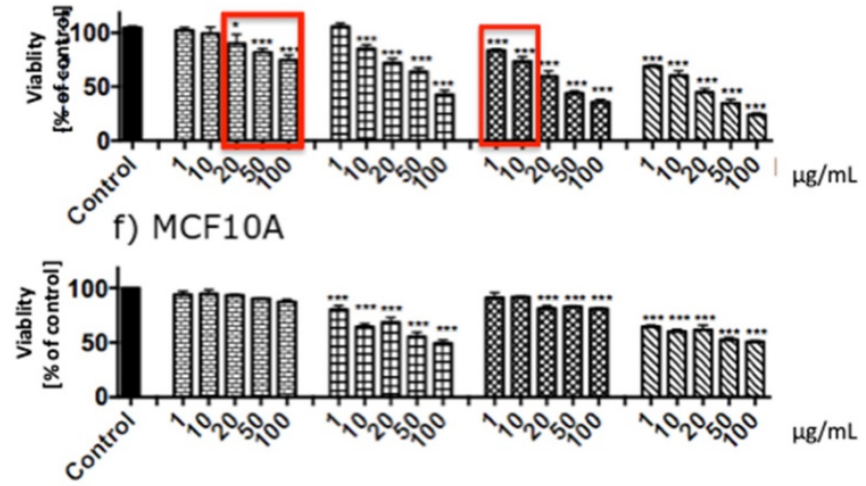

Control 율 AuNPs-GSH 回 AuNPs-GSH-DOX

因 AuNPs-GSH-CTA $\mathbb{Q}$ AuNPs-GSH-GEM

Figure 8. AuNPs-GSH conjugated with chemotherapeutics: DOX, GEM, CTA decreased viability of the cells in a concentration-dependent manner after $24 \mathrm{~h}$ of incubation. The viability measured by MTT assay of (a) 143B, (b) hFOB 1.19, (c) PNAC-1, (d) hTERT-HPNE, (e) MCF7 and (f) MCF10A cells exposed to AuNPs for 24h. Data are presented as mean $\pm S D$. ${ }^{*} p<0.05, * * p<0.01, * * * p<0.001$. Red boxes indicate selective cytotoxicity of AuNPs only to cancer cells (in comparison to non-transformed cells).

a)

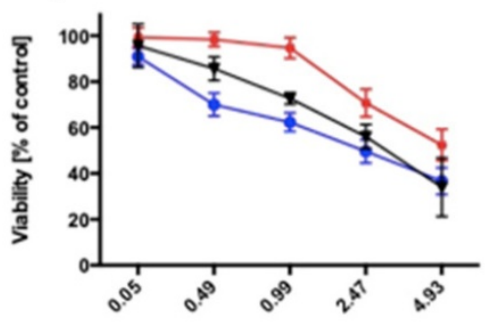

Gemcytabine $[\mu \mathrm{g} / \mathrm{mL}]$ b)

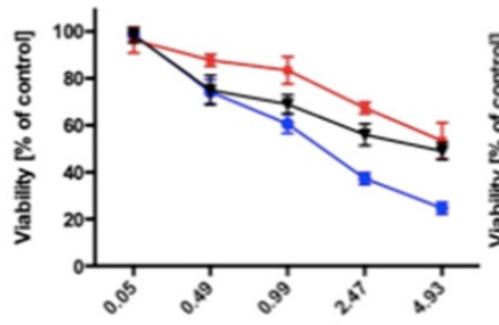

Doxorubicin $[\mu \mathrm{g} / \mathrm{mL}]$ c)

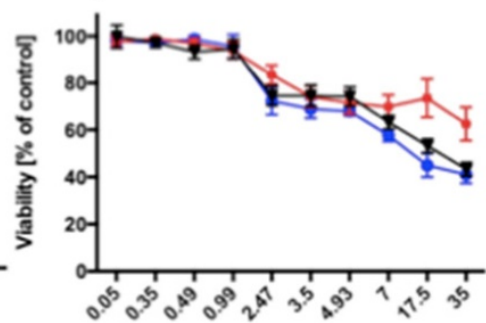

Cytarabine $[\mu \mathrm{g} / \mathrm{mL}]$

Figure 9. Chemotherapeutics decreased the viability of the cancer cells in a concentration-dependent manner. Viability measured by MTT assay of the $143 \mathrm{~B}$, PANC-1 and MCF7 cells exposed to (a) GEM, (b) DOX and (c) CTA for $24 \mathrm{~h}$. The viability of control was set to $100 \%$. Data are presented as mean \pm SD. 
In the conditions listed below, our AuNPschemotherapeutic conjugates significantly decreased the viability of cancer cells, whereas corresponding chemotherapeutic concentrations did not. AuNPs-GSH-DOX (1 $\mu \mathrm{g} / \mathrm{mL})$, AuNPs-GSH-CTA (1, 10, 20, $50 \mu \mathrm{g} / \mathrm{mL}$ ) on 143B cells; AuNPs-GSH-CTA $(10,20,50 \mu \mathrm{g} / \mathrm{mL})$, AuNPs-GSH-GEM (1, 10, 20 $\mu \mathrm{g} / \mathrm{mL})$ on PANC-1 cells; AuNPs-GSH-CTA $(1,10$, 20, $50 \mu \mathrm{g} / \mathrm{mL})$ and AuNPs-GSH-GEM $(1,10 \mu \mathrm{g} / \mathrm{mL})$ on MCF7cells, respectively.

Importantly, tested AuNPs had anti-cancer potential. Nanoparticles coated only with GSH had the smallest impact on the viability of the cells. Furthermore, tumor cells line were more susceptible to tested AuNPs that non-transformed cell lines. As mentioned above AuNPs conjugated with chemotherapeutics exerted selective cytotoxicity.

\section{Discussion}

In 2018, more than 18 million people were diagnosed with cancer and 9.5 million people died of it [25]. Among cancers: breast cancer (>2 088000 new cases, >626000 deaths in 2018), pancreatic cancer (>458 000 new cases, 432000 deaths in 2018) and osteosarcoma (morbidity rate of 4 cases/million people yearly), are emerging clinical problems $[25,26]$. Unfortunately, prognosis in those cancers is poor. Only $60 \%$ of patients with osteosarcoma and breast cancer survive at least 5 years from diagnosis, whereas almost no patients with pancreatic cancer survive 5 years (median survival 5.5 months) [26-28]. Moreover, the treatment of cancer: chemotherapy, radiotherapy, hormonotherapy, and surgery severely decrease patients' quality of life. Among the others: myelosuppression, hepatotoxicity, renal failure, heart failure, gastrointestinal tract damage, nausea and hair loss are the most important side effect of chemotherapy $[15,22,23]$. Therefore, novel approaches with better effectiveness and less severe side effects are needed.

The main aim of the study was to evaluate the anti-tumor and safety of AuNPs stabilized with GSH and conjugated with chemotherapeutics under in vitro condition. We decided to use AuNPs as it had been proven that they have a good safety profile and established a role as a drug delivery platform $[29,30]$. Furthermore, our nanoparticles are coated with GSH in order to increase biocompatibility [13]. Indeed, we have shown that AuNPs-GSH had small effects on the viability of mammalian cells. Importantly, typically AuNPs conjugated with chemotherapeutics have a higher impact on the viability of cancer cell lines than non-transformed ones. Furthermore, in some concentrations of AuNPs-chemotherapeutics, we were able to show selective cytotoxicity. Differences in effects exerted by AuNPs-chemotherapeutic and chemotherapeutic alone may be due to a different way of internalization. The drug can be internalized by passive diffusion whereas when conjugated with AuNPs internalization mechanism is endocytosis or other active transport mechanisms [31]. More importantly AuNPs-chemotherapeutic conjugate, in some cases, were more effective than chemotherapeutic alone. We compared the cytotoxicity of chemotherapeutics on cell lines used in this study (143B, PANC-1, MCF7) with literature data, and generally, we had similar results $[31,32,41,42,33-$ 40]. For DOX, Kamba et al., reported that $\mathrm{IC}_{50}$ was around $0.5 \mu \mathrm{g} / \mathrm{mL}$ (MG63, osteosarcoma cells), Yui et al, showed that $\mathrm{IC}_{50}$ was approximately equal 2 $\mu \mathrm{g} / \mathrm{mL}$ (PANC1 cells).

Data on cytotoxicity of AuNPs-GSH or AuNPs conjugated with chemotherapeutics are limited. However, several studies have proven the safety of AuNPs. Leite et al, have demonstrated that $4.5 \mathrm{~nm}$ PEG-AuNPs in concentration up to $5 \times 10^{13}$ particles/mL did not influence the viability of mouse myoblastoma ( $\mathrm{C} 2 \mathrm{C} 12$ cells) measured by MTT assay [43]. Similarly, $\mathrm{IC}_{50}$ of HeLa cells treated with $1.4 \mathrm{~nm}$ GSH-coated AuNPs was $3130 \mu \mathrm{M}$. In our study, which was similar to already published data, AuNPsGSH had the lowest cytotoxicity potential, which have proven that functionalization of AuNPs with GSH ensures good safety-profile of synthesized AuNPs. Size of AuNPs is one of the main factors impacting AuNPs cytotoxicity [44]. Pan et al have examined the cytotoxicity of spherical AuNPs against human cell lines (fibroblast, melanoma, epithelial cells, and macrophages). They have chosen AuNPs in size range between 0.8 and $15 \mathrm{~nm}$ [44]. $1.4 \mathrm{~nm}$ AuNPs were the most cytotoxic whereas $15 \mathrm{~nm}$ AuNPs were 60-100 times less toxic [44].

Manivasagan et al. assessed potential anti-cancer AuNPs-fucoidan-DOX on human breast adenocarcinoma cells (MDA-MB-231). Similarly to our results they have shown that AuNPs coated with DOX had a higher impact on cancer cells viability than AuNPs-fucoidan or DOX alone [45]. Correspondingly, Venkatourwar et al., assessed the impact of porphyrin-coated AuNPs conjugated with DOX as a potential drug delivery platform. They also showed that conjugated DOX and AuNPs are more cytotoxic against human glioma cells (LN-299) than any of the compounds alone [46].

According to best of our knowledge, it is the first study to examine the impact of CTA conjugated metal nanoparticles on mammalian cells in which we indicated that AuNPs stabilized with GSH and conjugated with CTA can be more effective in 
inducing cell death that CTA alone on osteosarcoma, pancreatic cancer cells breast cancer cells.

We have found that AuNPs may be an interesting drug delivery platform. AuNPschemotherapeutic conjugates may be more effective than the drug alone and can have a selective effect only on cancer cells. AuNPs-chemotherapeutic conjugates allow using lesser concentration (dose) of the drug, which decreases the severity of side effects and reduces the treatment cost.

\section{Conclusions}

In the presented study, we demonstrated the anti-cancer potential of AuNPs stabilized with GSH and conjugated with chemotherapeutics. We have shown that our nanoparticles can be selectively cytotoxic to cancer cell lines (in comparison to non-transformed ones). Furthermore, in some cases, synthesized AuNPs conjugates were more effective than the drug alone. Modern methods of chemical synthesis of nanoparticles conjugated with chemotherapeutics may increase the effectiveness of anti-cancer therapy. At the same time, it allows for a significant reduction of treatment costs and relieves of side effects.

\section{Abbreviations}

GEM: gemcitabine; DOX: doxorubicin; CTA: cytarabine; NPs: nanoparticles; AuNPs: gold nanoparticles; GSH: glutathione; $\mathrm{HAuCl}_{4}$ : chloroauric acid; TEM: transmission electron microscopy; TGA: thermogravimetric analysis; NMR: nuclear magnetic resonance spectroscopy; HPLC: high-performance liquid chromatography.

\section{Acknowledgments}

MCF7 and MCF10A cells were a kind gift from prof. Anna Herman-Antosiewicz from the University of Gdansk.

\section{Funding}

This work was supported by the Grant from the Medical University of Gdansk, Poland (ST-02-705 $0046 / 07 / 259$ ). The funders had no role in study design, data collection, and analysis, decision to publish, or preparation of the article.

\section{Authors' contributions}

All authors contributed to the study conception and design. KPS, EB, KS and ET performed material preparation, data collection and analysis. IIS and MW provided supervision. The first draft of the manuscript was written by KPS and all authors commented on previous versions of the manuscript. All authors read and approved the final manuscript.

\section{Competing Interests}

The authors have declared that no competing interest exists.

\section{References}

1. Dalrymple KL, Martinez J, Rosenstein L, Kneeland ET, Zimmerman M. Psychiatric disorder-weight associations and the moderating effect of sex in an outpatient psychiatric sample. Ann. Clin. Psychiatry. 2015;27:108-117.

2. Tangka FK, Trogdon JG, Richardson LC, Howard D, Sabatino SA, Finkelstein EA. Cancer treatment cost in the United States: Has the burden shifted over time? Cancer. 2010;116:3477-3484.

3. Lee U, Yoo C-J, Kim Y-J, Yoo Y-M. Cytotoxicity of gold nanoparticles in human neural precursor cells and rat cerebral cortex. J. Biosci. Bioeng. 2016;121:341-344.

4. Ahn JM, Eom HJ, Yang X, Meyer JN, Choi J. Comparative toxicity of silver nanoparticles on oxidative stress and DNA damage in the nematode, Caenorhabditis elegans. Chemosphere. 2014;108:343-352.

5. Gromnicova R, Kaya M, Romero IA, et al. Transport of gold nanoparticles by vascular endothelium from different human tissues. PLoS One. 2016;11:1-17.

6. Ho BN, Pfeffer CM, Singh ATK. Update on Nanotechnology-based Drug Delivery Systems in Cancer Treatment. Anticancer Res. 2017;37:5975-5981.

7. Gu YJ, Cheng J, Man CWY, Wong WT, Cheng SH. Gold-doxorubicin nanoconjugates for overcoming multidrug resistance. Nanomedicine Nanotechnology, Biol. Med. 2012;8:204-211.

8. Banu H, Sethi DK, Edgar A, et al. Doxorubicin loaded polymeric gold nanoparticles targeted to human folate receptor upon laser photothermal therapy potentiates chemotherapy in breast cancer cell lines. J. Photochem. Photobiol. B Biol. 2015;149:116-128.

9. Mahmoodi NO, Ghavidast A, Amirmahani N. A comparative study on the nanoparticles for improved drug delivery systems. Journal of Photochemistry and Photobiology B: Biology. 2016;162:681-693.

10. Brown SD, Nativo P, Smith JA, et al. Gold nanoparticles for the improved anticancer drug delivery of the active component of oxaliplatin. J. Am. Chem. Soc. 2010;132:4678-4684.

11. Zabielska-Koczywas K, Dolka I, Król M, et al. Doxorubicin conjugated to glutathione stabilized gold nanoparticles (Au-GSH-Dox) as an effective therapeutic agent for feline injection-site sarcomas - Chick embryo chorioallantoic membrane study. Molecules. 2017;22:253.

12. Simpson CA, Salleng KJ, Cliffel DE, Feldheim DL. In vivo toxicity, biodistribution, and clearance of glutathione-coated gold nanoparticles. Nanomedicine Nanotechnology, Biol. Med. 2013;9:257-263.

13. Liu Y, Ma W, Liu W, et al. Silver(i)-glutathione biocoordination polymer hydrogel: Effective antibacterial activity and improved cytocompatibility. J. Mater. Chem. 2011;21:19214-19218.

14. Kamisawa T, Wood LD, Itoi T, Takaori K. Pancreatic cancer. Lancet. 2016;388:73-85.

15. Kubicka S, Rudolph KL, Tietze MK, Lorenz M, Manns M. Phase II study of systemic gemcitabine chemotherapy for advanced unresectable hepatobiliary carcinomas. Hepatogastroenterology. 2001;48:783-789.

16. Du W, Touchette D, Vaitkevicius V, Peters W, Shields A. Cost Analysis of Pancreatic Carcinoma Treatment. Cnacer. 2000;89:1917-1924.

17. Rahib L, Smith BD, Aizenberg R, Rosenzweig AB, Fleshman JM, Matrisian LM. Projecting cancer incidence and deaths to 2030: The unexpected burden of thyroid, liver, and pancreas cancers in the united states. Cancer Research. 2014;74:2913-2921.

18. Luetke A, Meyers PA, Lewis I, Juergens H. Osteosarcoma treatment - Where do we stand? A state of the art review. Cancer Treat. Rev. 2014;40:523-532.

19. Steckiewicz KP, Barcinska E, Malankowska A, et al. Impact of gold nanoparticles shape on their cytotoxicity against human osteoblast and osteosarcoma in in vitro model . Evaluation of the safety of use and anti-cancer potential. J. Mater. Sci. Mater. Med. 2019;30:1-15.

20. Cohen O, Lam G, Choi M, Karp N, Ceradini D. Does the Timing of Chemotherapy Affect Post-Mastectomy Breast Reconstruction Complications? Clin. Breast Cancer. 2017;17:307-315.

21. Niwińska A, Rudnicka H, Murawska M. Breast cancer leptomeningeal metastasis: The results of combined treatment and the comparison of methotrexate and liposomal cytarabine as intra-cerebrospinal fluid chemotherapy. Clin. Breast Cancer. 2015;15:66-72.

22. Speth PAJ, van Hoesel QGCM, Haanen C. Clinical Pharmacokinetics of Doxorubicin. Clinical Pharmacokinetics. 1988;15:15-31.

23. Juel-Jensen BE. Severe generalized primary herpes treated with cytarabine. Br. Med. J. 1970;2:154-5.

24. Steckiewicz KP, Zwara J, Jaskiewicz M, et al. Shape-Depended Biological Properties of $\mathrm{Ag} 3$ PO 4 Microparticles: Evaluation of Antimicrobial Properties and Cytotoxicity in In Vitro Model - Safety Assessment of Potential Clinical Usage. 2019.

25. Bray F, Ferlay J, Soerjomataram I, Siegel RL, Torre LA, Jemal A. Global cancer statistics 2018: GLOBOCAN estimates of incidence and mortality worldwide for 36 cancers in 185 countries. CA. Cancer J. Clin. 2018;68:394-424.

26. Savage SA, Mirabello L. Using epidemiology and genomics to understand osteosarcoma etiology. Sarcoma. 2011;2011:14-16. 
27. Von Hoff DD, Ervin T, Arena FP, et al. Increased survival in pancreatic cancer with nab-paclitaxel plus gemcitabine. N. Engl. J. Med. 2013;369:1691-1703.

28. Gakwaya A, Kigula-Mugambe JB, Kavuma A, et al. Cancer of the breast: 5-Year survival in a tertiary hospital in Uganda. Br. J. Cancer. 2008;99:63-67.

29. Paciotti GF, Kingston DGI, Tamarkin L. Colloidal gold nanoparticles: A novel nanoparticle platform for developing multifunctional tumor-targeted drug delivery vectors. Drug Development Research. 2006;67:47-54.

30. Guglielmo C Di, Lapuente J De, Porredon C, Ramos-López D, Sendra J, Borrás M. In Vitro Safety Toxicology Data for Evaluation of Gold NanoparticlesChronic Cytotoxicity, Genotoxicity and Uptake. J. Nanosci. Nanotechnol. 2012;12:6185-6191.

31. Kamba SA, Ismail M, Hussein-Al-Ali SH, Ibrahim TAT, Zakaria ZAB. In vitro delivery and controlled release of doxorubicin for targeting osteosarcoma bone cancer. Molecules. 2013;18:10580-10598.

32. Yin F, Yang C, Wang Q, et al. A light-driven therapy of pancreatic adenocarcinoma using gold nanorods-based nanocarriers for co-delivery of doxorubicin and siRNA. Theranostics. 2015;5:818-833.

33. Varbanov HP, Kuttler F, Banfi D, Turcatti G, Dyson PJ. Repositioning approved drugs for the treatment of problematic cancers using a screening approach. PLoS One. 2017;12:1-16.

34. Jenie RI, Handayani S, Susidarti RA, Udin LZ, Meiyanto E. The cytotoxic and antimigratory activity of Brazilin-doxorubicin on MCF-7/HER2 cells. Adv. Pharm. Bull. 2018;8:507-516.

35. Zhang $\mathrm{P}$, Yi W, Hou J, Yoo S, Jin W, Yang Q. Acarbon nanotube-gemcitabine-lentinan three-component composite for chemo-photothermal synergistic therapy of cancer. Int. J. Nanomedicine. 2018;13:3069-3080.

36. Xu Y, Huang Y, Zhang X, Lu W, Yu J, Liu S. Carrier-free Janus nano-prodrug based on camptothecin and gemcitabine: Reduction-triggered drug release and synergistic in vitro antiproliferative effect in multiple cancer cells. Int. J. Pharm. 2018;550:45-56.

37. Lev-Ari S, Vexler A, Starr A, et al. Curcumin augments gemcitabine cytotoxic effect on pancreatic adenocarcinoma cell lines. Cancer Invest. 2007;25:411-418.

38. Zheng C, Jiao X, Jiang Y, Sun S. ERK1/2 activity contributes to gemcitabine resistance in pancreatic cancer cells. J. Int. Med. Res. 2013;41:300-360.

39. Popescu RC, Andronescu E, Vasile B Ștefan, et al. Fabrication and cytotoxicity of gemcitabine-functionalized magnetite nanoparticles. Molecules. 2017;22.

40. Anantharaman NV, Udhumansha U, Rathnam G, Metha CLB. ISSN : 2320-2831 In-vitro diffusion studies and anticancer activity of cytarabine loaded nanocochleates against MCF-7 cell lines. 2018;7:285-294.

41. Wang Y, Wang S, Liu J, Lu Y, Li D. Licoricidin enhances gemcitabine-induced cytotoxicity in osteosarcoma cells by suppressing the Akt and NF-kB signal pathways. Chem. Biol. Interact. 2018;290:44-51.

42. Choupani J, Alivand MR, M. Derakhshan S, Zaeifizadeh M, S. Khaniani M. Oleuropein inhibits migration ability through suppression of epithelial-mesenchymal transition and synergistically enhances doxorubicin-mediated apoptosis in MCF-7 cells. J. Cell. Physiol. 2018;1-12. doi:10.1002/jcp. 27586

43. Leite PEC, Pereira MR, Santos CA do N, Campos APC, Esteves TM, Granjeiro JM. Gold nanoparticles do not induce myotube cytotoxicity but increase the susceptibility to cell death. Toxicol. Vitr. 2015;29:819-827.

44. Pan Y, Neuss S, Leifert A, et al. Size-dependent cytotoxicity of gold nanoparticles. Small. 2007;3:1941-1949.

45. Manivasagan $\mathrm{P}$, Bharathiraja $\mathrm{S}, \mathrm{Bui} \mathrm{NQ}$, et al. Doxorubicin-loaded fucoidan capped gold nanoparticles for drug delivery and photoacoustic imaging. Int. J. Biol. Macromol. 2016;91:578-588.

46. Venkatpurwar V, Shiras A, Pokharkar V. Porphyran capped gold nanoparticles as a novel carrier for delivery of anticancer drug: In vitro cytotoxicity study. Int. J. Pharm. 2011;409:314-320. 